\title{
Effect of singlet oxygen generating substances on the ascorbic acid and glutathione content in pea leaves
}

\author{
Gábor Gullner*, Alan D. Dodge \\ School of Biological Sciences, University of Bath, Claverton Down, Bath BA2 7AY, Avon, UK
}

Received 19 April 1999; received in revised form 16 November 1999; accepted 16 November 1999

\begin{abstract}
Ascorbate and glutathione levels were investigated in pea leaf discs exposed to various singlet oxygen generating compounds: eosin, rose bengal, monuron, acifluorfen and 5-amino-levulinic acid (ALA). The cellular level of the major antioxidant ascorbate was markedly decreased by the herbicides monuron, acifluorfen and ALA (in light-dependent reactions), as well as by the xanthene dyes eosin and rose bengal (independently of light). No significant accumulation of dehydroascorbate could be observed in any treatments. In contrast to ascorbate, the foliar glutathione levels were considerably increased by subtoxic or slightly toxic concentrations of eosin, rose bengal, acifluorfen and ALA in a light-dependent manner. Monuron treatments led to unchanged or decreasing glutathione contents. The activities of three antioxidative enzymes (ascorbate peroxidase, glutathione reductase and glutathione $S$-transferase) were also induced by eosin in light-dependent reactions. C 2000 Published by Elsevier Science Ireland Ltd. All rights reserved.
\end{abstract}

Keywords: Acifluorfen; 5-Aminolevulinic acid; Ascorbate; Glutathione; Monuron; Xanthene dye

\section{Introduction}

The accumulation of active oxygen species (AOSs) has been observed in various plants exposed to biotic and abiotic stress effects [1]. Among other AOSs, singlet oxygen $\left({ }^{1} \mathrm{O}_{2}\right)$, the excited form of molecular oxygen is also capable of damaging important plant cell constituents [2-4]. Singlet oxygen sources in biological systems include light-dependent reactions (photosensitization) and chemical generations in dark reactions [5].

A large variety of dyes act as photosensitizers. The cell damaging effects of the xanthene dyes

Abbreviations: ALA, 5-aminolevulinic acid; AOS, active oxygen species; AP, ascorbate peroxidase; DHA, dehydroascorbate; GR, glutathione reductase; GSH, glutathione; GSSG, oxidized glutathione; GST, glutathione $S$-transferase.

* Corresponding author. Present address: Plant Protection Institute, Hungarian Academy of Sciences, P.O.B. 102, H-1525 Budapest, Hungary. Tel.: + 36-1-355-8722; fax: + 36-1-356-3698.

E-mail address: ggull@nki.hu (G. Gullner) eosin and rose bengal are well known in plant leaves $[2,6,7]$. The light excitation energy of these dyes is transferred directly to dioxygen, leading to the generation of singlet oxygen.

Chlorophyll itself is capable of photodynamic reactions involving ${ }^{1} \mathrm{O}_{2}$ when its excited states are insufficiently quenched by the photosystems or by carotenoids [3,6]. Phenylurea herbicides, such as monuron (3-[ $p$-chlorophenyl]-1,1-dimethylurea), promote these reactions by blocking the electron flow between the photosystems [6]. Other porphyrin derivatives are also effective photosensitizers [8]. These intermediates are normally present in small amounts, but an excess might act as photosensitizer because they are unable to pass on light excitation energy to light harvesting accessory proteins. Instead, excitation energy results in triplet state senzitizers, which excite oxygen to the singlet state. The herbicide acifluorfen (5-[2-chloro-4-(trifluoromethyl)-phenoxy]-2-nitrobenzoic acid), which exerts its effect in the light, is known to induce the accumulation of protopor- 
phyrin IX and other tetrapyrrole derivatives in plant leaves $[9,10]$. The chlorophyll precursor 5aminolevulinic acid (ALA) can also cause accumulation of abnormally high levels of tetrapyrrole intermediates in darkness if it is added exogenously. As a consequence, ALA treatments led to marked photodynamic herbicidal effects $[4,8,11]$.

Plants are protected by various mechanisms against the oxidative stress caused by singlet oxygen. Membrane bound antioxidants, carotenoids and $\alpha$-tocopherols are well-known quenchers of ${ }^{1} \mathrm{O}_{2}[2,3]$. However, much less information, mostly from in vitro studies, is available about the role of water-soluble antioxidants in the detoxification of singlet oxygen. Ascorbate is a major primary antioxidant, which reacts directly with singlet oxygen $[1,12]$. Glutathione $(\mathrm{GSH})$ is also known to scavenge ${ }^{1} \mathrm{O}_{2}$ [1,5]. Ascorbate and GSH are closely related as both are constituents of the antioxidative ascorbate-glutathione cycle which detoxifies hydrogen peroxide in the chloroplasts [1].

In order to gain more information about the role of ascorbate and GSH in the detoxification of singlet oxygen in plant tissues, we have studied their cellular levels in pea leaf discs exposed to various ${ }^{1} \mathrm{O}_{2}$ generating substances (eosin, rose bengal, monuron, acifluorfen and ALA). In addition, the activities of the antioxidative enzymes ascorbate peroxidase (AP; E.C. 1.11.1.11.), glutathione reductase (GR; E.C. 1.6.4.2.) and glutathione $S$ transferase (GST; E.C. 2.5.1.18.) were also investigated in pea leaf discs exposed to eosin. AP and GR are constituents of the ascorbate-glutathione cycle [1]. GST, beside other detoxification reactions, can catalyze the breakdown of fatty-acid hydroperoxides and contributes to the protection of plant cells against oxidative membrane damage $[13,14]$.

\section{Materials and methods}

\subsection{Plant material}

Pea (Pisum sativum L. var. Meteor) seedlings were grown in Levington Universal compost in a greenhouse with a $14 \mathrm{~h}$ photoperiod (natural daylight extended by $400 \mathrm{~W}$ Thorn mercury vapour lamps) and a mean air temperature of $22^{\circ} \mathrm{C}$. Leaf discs (12 $\mathrm{mm}$ in diameter) were excised from subapical leaves of 2-3 week-old pea plants. Discs were floated on the aqueous solutions of singlet oxygen generators (or on tap water) in Petri dishes for $24 \mathrm{~h}$ in darkness, then they were exposed to continuous light for $72 \mathrm{~h}$ in a light cabinet maintained at $25^{\circ} \mathrm{C}$. Illumination $\left(400 \mu \mathrm{mol} \mathrm{m} \mathrm{m}^{-2} \mathrm{~s}^{-1}\right)$ was provided by warm fluorescent tubes $(65 / 85-\mathrm{W}$; Thorn). After varying time periods the leaf discs were washed and used for biochemical assays. Parallel incubations were carried out in darkness. Dry leaf weights were measured after the incubation of leaf discs at $110^{\circ} \mathrm{C}$ for $2 \mathrm{~h}$.

ALA, eosin Y $\left(2^{\prime}, 4^{\prime}, 5^{\prime}, 7^{\prime}\right.$-tetrabromofluorescein $)$, and rose bengal (4,5,6,7-tetrachloro- $2^{\prime}, 4^{\prime}, 5^{\prime}, 7^{\prime}$-tetraiodofluorescein) were obtained from Sigma (St. Louis, MO, USA). Acifluorfen and monuron were purchased from Riedel-de Haen (Seelze, Germany).

\subsection{Enzyme assays}

For enzyme assays cell-free homogenates were prepared at $0-4^{\circ} \mathrm{C}$. Leaf material $(0.5 \mathrm{~g})$ was frozen in liquid nitrogen, pulverized with a mortar and a pestle, and suspended in $3 \mathrm{ml}$ of ice-cold 0.2 $\mathrm{M}$ Tris- $\mathrm{HCl}$ buffer $(\mathrm{pH} 7.8)$ containing $3 \%$ soluble polyvinylpyrrolidone and $0.1 \mathrm{mM} \mathrm{Na} \mathrm{m}_{2}$-EDTA. The homogenate was strained through muslin and centrifuged at $8000 \times g$ for $20 \mathrm{~min}$. The supernatants were used as enzyme source.

The enzyme activities were determined by spectrophotometric methods. The activity of AP was determined as described in Ref. [13], except that in our experiments $0.25 \mathrm{mM}$ ascorbate and $0.5 \mathrm{mM}$ hydrogen peroxide were used. GR and GST activities were measured by following the reduction of oxidized glutathione (GSSG) at $340 \mathrm{~nm}$, and by measuring the formation of the GSH-conjugate using 1-chloro-2,4-dinitrobenzene as substrate at $340 \mathrm{~nm}$, respectively, as described earlier [13].

\subsection{Other assays}

The level of acid-soluble, non-protein thiols was measured spectrophotometrically with 5,5'-dithiobis-(2-nitrobenzoic acid) according to De Kok and Graham [15]. Parallel with the thiol measurements, total glutathione (GSH + GSSG) contents were also determined in the plant extracts with a specific enzymatic method using GR as described by Smith [16]. 
Ascorbate and dehydroascorbate levels were measured by enzymatic methods using ascorbate oxidase enzyme as described by Wise and Naylor [17], and Foyer et al. [18], respectively.

\subsection{Statistics}

At least three independent parallel experiments were carried out in each case. The significant differences between mean values were evaluated by Student's $t$-test. Differences were considered to be significant at $P=0.05$.

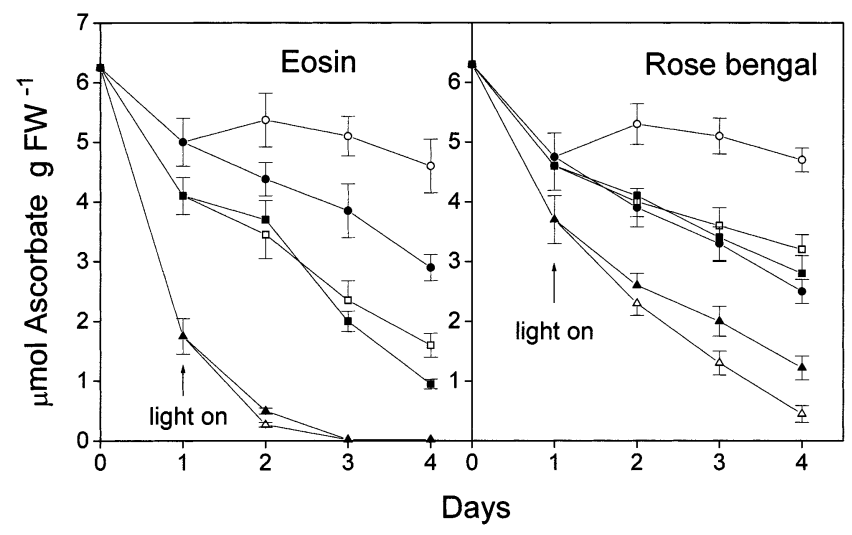

Fig. 1. Changes in the ascorbate content of pea leaf discs exposed to xanthene dyes (eosin or rose bengal) at various concentrations. All discs were preincubated for $24 \mathrm{~h}$ in darkness then illuminated $\left(400 \mu \mathrm{mol} \mathrm{m} \mathrm{m}^{-2} \mathrm{~s}^{-1}\right)$. Parallel experiments were carried out in darkness. Means of three independent experiments \pm S.D. are shown. Symbols, illuminated discs: $\bigcirc$, control; $\square, 10 \mu \mathrm{M}$ dye; $\triangle, 1 \mathrm{mM}$ dye. In darkness: $\boldsymbol{\bullet}$, control; $\mathbf{\square}, 10 \mu \mathrm{M}$ dye; and $\boldsymbol{\Lambda}, 1 \mathrm{mM}$ dye.

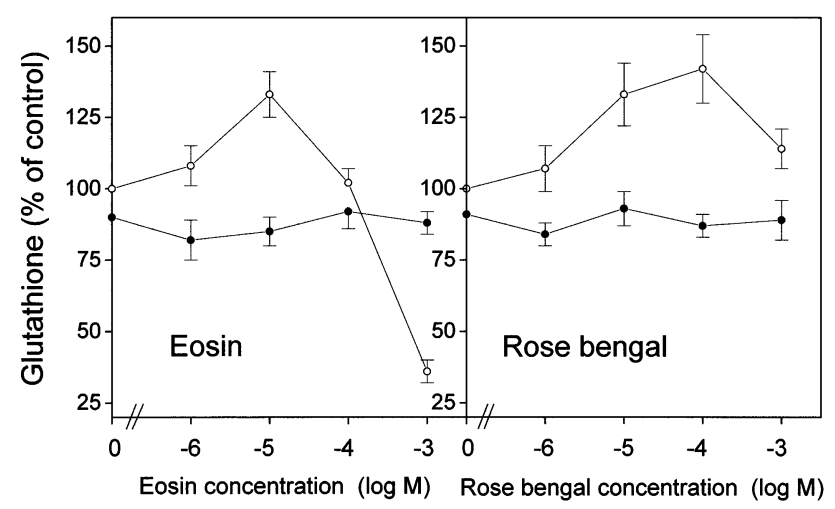

Fig. 2. Changes in the total glutathione level of pea leaf discs incubated with eosin or rose bengal at various concentrations for $24 \mathrm{~h}$ under illumination $\left(400 \mu \mathrm{mol} \mathrm{m}{ }^{-2} \mathrm{~s}^{-1}\right)$ preceeded by $24 \mathrm{~h}$ preincubation in darkness. The values presented are percentages of the glutathione level in illuminated control leaf discs $\left(0.46 \pm 0.04 \mu \mathrm{mol}\right.$ glutathione $\left.\mathrm{g} \mathrm{FW}^{-1}\right)$. Means of three independent experiments \pm S.D. are shown. Symbols: $\bigcirc$, illuminated leaf discs; and ${ }^{-}$, dark incubations.

\section{Results and discussion}

\subsection{Xanthene dyes}

The application of xanthene dyes to pea leaf discs resulted in phytotoxic symptoms (bleaching) in the light, but not in darkness. The exposure of illuminated pea leaf tissue to $10 \mu \mathrm{M}$ eosin led to only a very weak bleaching effect after $24 \mathrm{~h}$, but 1 $\mathrm{mM}$ eosin was markedly phytotoxic. Rose bengal was much less toxic than eosin: only as high as 1 $\mathrm{mM}$ rose bengal concentration caused visible symptoms (moderate bleaching) in pea leaf tissue.

Eosin, and to a lesser extent also rose bengal decreased the ascorbate content in a concentration-dependent manner. Xanthene dye treatments led to ascorbate degradation in both illuminated and dark-incubated leaf discs (Fig. 1). Since singlet oxygen can not be produced by xanthene dyes without the excitation energy of light, these results proved that the ascorbate degradation was not related to singlet oxygen quenching. The dehydroascorbate (DHA) levels also markedly decreased in the leaf discs exposed to xanthene dyes (data not shown). In untreated pea leaves DHA accounted for $26 \pm 6 \%(n=5)$ of the total ascorbic acid content. The light-independent reactions leading to the depletion of ascorbate and dehydroascorbate pools in the presence of xanthene dyes are not known. In darkness, ascorbate levels markedly declined also in untreated pea leaf discs as it had been observed earlier [19] showing that light was necessary for its synthesis or recycling.

In contrast to ascorbate, both the non-protein thiol and the total glutathione contents increased in pea leaf discs exposed to subtoxic or slightly toxic concentrations of the xanthene dyes under illumination. The maximal increases were found after $24 \mathrm{~h}$ (Fig. 2), later the thiol and GSH levels slowly returned to control levels. However, at the very toxic $1 \mathrm{mM}$ eosin concentration a dramatic GSH loss was found. Similar results were obtained when GSH levels were calculated on dry weight basis (data not shown). In darkness, the GSH content of untreated leaf discs slightly decreased as observed earlier in other plants [20]. The xanthene dyes did not alter the total glutathione levels in darkness as compared to dark controls.

Increases in GSH levels were often observed in plants in response to oxidative stimuli [14,21,22]. The rate-limiting step of GSH biosynthesis is cata- 
Table 1

Activities of ascorbate peroxidase (AP), glutathione reductase (GR), and glutathione $S$-transferase (GST) in pea leaf discs exposed to various concentrations of eosin ${ }^{\mathrm{a}}$

Eosin concentration Enzyme activities (\% of illuminated control $)^{\mathrm{b}}$

AP GR GST

\begin{tabular}{cccc}
\hline In the light & & & \\
$1 \mu \mathrm{M}$ & $116 \pm 15$ & $118 \pm 17$ & $103 \pm 7$ \\
$10 \mu \mathrm{M}$ & $159 \pm 9$ & $151 \pm 16$ & $121 \pm 13$ \\
$100 \mu \mathrm{M}$ & $135 \pm 14$ & $156 \pm 10$ & $123 \pm 5$ \\
$1 \mathrm{mM}$ & $39 \pm 5$ & $34 \pm 2$ & $20 \pm 2$
\end{tabular}

In darkness

$\begin{array}{cccc}10 \mu \mathrm{M} & 75 \pm 6 & 127 \pm 11 & 82 \pm 8 \\ 1 \mathrm{mM} & 67 \pm 9 & 95 \pm 4 & 80 \pm 9\end{array}$

${ }^{a}$ Leaf discs were preincubated in darkness for $24 \mathrm{~h}$ then illuminated $\left(400 \mu \mathrm{mol} \mathrm{m}{ }^{-2} \mathrm{~s}^{-1}\right)$ for $24 \mathrm{~h}$. Parallel incubations were carried out in darkness. Means of three different experiments \pm S.D. are shown.

${ }^{\mathrm{b}}$ Enzyme activities in illuminated control leaves were $2.6 \pm$ $0.3 \mu \mathrm{mol}$ ascorbate $\mathrm{g} \mathrm{FW}^{-1} \mathrm{~min}^{-1}, 1.5 \pm 0.1 \mu \mathrm{mol}$ NADPH g $\mathrm{FW}^{-1} \mathrm{~min}^{-1}$, and $0.61 \pm 0.7 \mu \mathrm{mol}$ conjugate $\mathrm{g} \mathrm{FW}^{-1}$ $\min ^{-1}$ for AP, GR and GST, respectively, $(n=5)$.

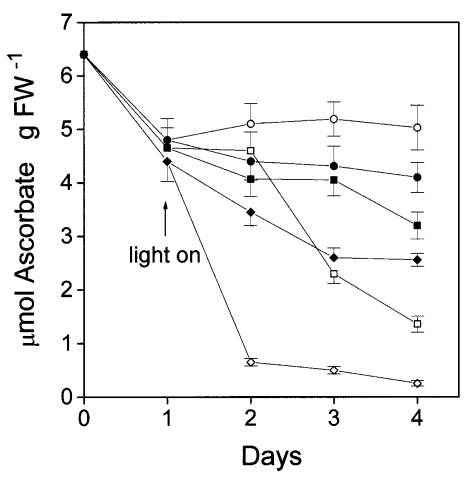

Fig. 3. Ascorbate levels in pea leaf discs exposed to various concentrations of monuron. All discs were preincubated for $24 \mathrm{~h}$ in darkness then illuminated $\left(400 \mu \mathrm{mol} \mathrm{m} \mathrm{m}^{-2} \mathrm{~s}^{-1}\right)$, except in the parallel dark incubations. Means of three independent experiments \pm S.D. are shown. Symbols, illuminated discs: $\bigcirc$, control; $\square, 10 \mu \mathrm{M}$ monuron; and $\diamond, 100 \mu \mathrm{M}$ monuron. In darkness: $\bullet$, control; $\mathbf{\square}, 10 \mu \mathrm{M}$ monuron; and $\diamond, 100 \mu \mathrm{M}$ monuron.

lyzed by the enzyme $\gamma$-glutamylcysteine synthetase [21]. A recent report demonstrated the rapid posttranscriptional activation of this enzyme during various plant stress responses in Arabidopsis suspension cultures. Discrete signal transduction pathways permit discrimination between different stress effects [22]. To meet the increased demand for the intermediate cysteine the assimilatory sul- fate reduction is also activated in plants exposed to stress effects [21]. The effects of singlet oxygen generators on these biosynthetic pathways are not known.

In our experiments, the total glutathione content accounted for $92 \pm 5 \%(n=4)$ of the nonprotein thiol level in the untreated leaves. Alterations of the non-protein thiol level after dye treatments were nearly identical to those of the total glutathione (GSH + GSSG) level (data not shown). These results showed that no substantial increase in the ratio of GSSG to GSH was brought about by the xanthene dyes.

Eosin significantly induced also the activities of AP, GR and GST after $24 \mathrm{~h}$ in the light at 10-100 $\mu \mathrm{M}$ concentrations, but at $1 \mathrm{mM}$ it strongly inhibited each enzyme activity (Table 1). After 48 and $72 \mathrm{~h}$ incubations the activities shifted toward control values (data not shown). The induction of the enzymes was light-dependent (Table 1). The induction of AP, GR and GST was already observed earlier in various plants exposed to oxidative stress $[1,13,23]$. It is interesting to note that rose bengal treatments led to the accumulation of salicylic acid and the development of systemic induced resistance in tobacco leaves [7].

\subsection{Monuron}

In contrast to xanthene dyes, monuron treatments substantially decreased the ascorbate level in pea leaf tissue in a light-dependent manner. After $24 \mathrm{~h}$ of illumination, $100 \mu \mathrm{M}$ monuron, which caused weak visible bleaching, reduced the ascorbate level by $88 \%$ (Fig. 3). In the darkness, the ascorbate level decreased only by $23 \%$. These results show that the ascorbate pool was depleted by a photodynamic reaction, but further studies are necessary to confirm the role of singlet oxygen in this process. It is conceivable that the decrease of ascorbate level by monuron was mediated not only by degradation but also by changes in the ascorbate biosynthesis. A substantial amount of new information has been published recently on the biosynthetic pathways of ascorbate [24,25], but no information is available on the effects of singlet-oxygen generating compounds on these pathways. No significant increase of DHA level was found neither in dark nor in light experiments (data not shown). 
In contrast to the xanthene dyes, monuron treatments led to a slow decrease of GSH content in pea leaf tissues incubated in the light. At 100 $\mu \mathrm{M}$ concentration monuron caused a significant decrease of $\mathrm{GSH}$ only after $48 \mathrm{~h}$ of illumination (to $62 \%$ of control), but after $72 \mathrm{~h}$ the GSH levels shifted back toward control values. At $10 \mu \mathrm{M}$ monuron concentration no effect was found. In dark incubations $100 \mu \mathrm{M}$ monuron did not change significantly the GSH levels as compared to dark controls. Changes of non-protein thiol levels were similar to those of total glutathione levels after monuron treatments (data not shown).

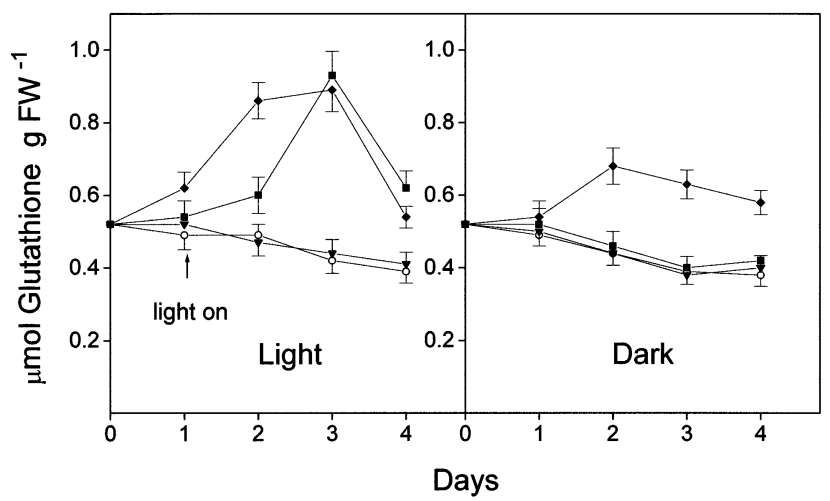

Fig. 4. Effect of acifluorfen on the total glutathione level in pea leaf discs. All discs were preincubated for $24 \mathrm{~h}$ in dark-

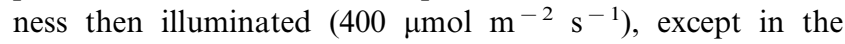
parallel dark incubations. Means of three independent experiments \pm S.D. are shown. Symbols: $\bigcirc$, control; $\nabla, 1 \mu \mathrm{M}$ acifluorfen; $\mathbf{\square}, 10 \mu \mathrm{M}$ acifluorfen; and $\bullet, 100 \mu \mathrm{M}$ acifluorfen.

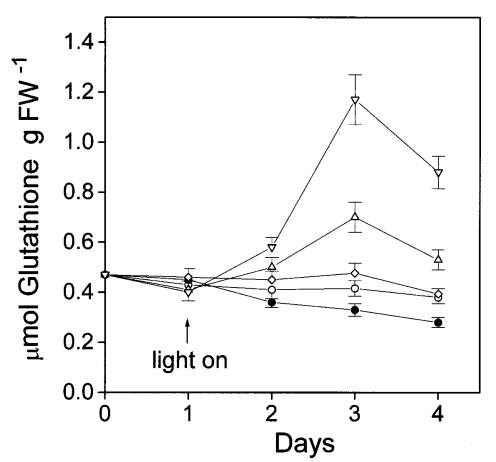

Fig. 5. Effect of 5-aminolevulinic acid (ALA) on the total glutathione level in pea leaf discs. All discs were preincubated for $24 \mathrm{~h}$ in darkness then illuminated $\left(400 \mu \mathrm{mol} \mathrm{m} \mathrm{m}^{-2} \mathrm{~s}^{-1}\right)$, except in parallel dark incubations. Means of three independent experiments \pm S.D. are shown. Symbols, illuminated discs: $\bigcirc$, control; $\diamond, 100 \mu \mathrm{M}$ ALA; $\triangle, 1 \mathrm{mM}$ ALA; and $\nabla$, 3 mM ALA. In darkness: control.

\subsection{Tetrapyrrole accumulation}

Applications of both acifluorfen (at $10 \mu \mathrm{M}$ or higher concentrations) and ALA (at $1 \mathrm{mM}$ and higher concentrations) led to visible bleaching symptoms on pea leaf discs after $24 \mathrm{~h}$ of illumination. The photodynamic herbicides did not cause any visible symptoms in dark incubations during a $96 \mathrm{~h}$ experimental period.

In the light, the exposure of leaf discs to $100 \mu \mathrm{M}$ acifluorfen strongly decreased the ascorbate level (to $31 \%$ of control after $48 \mathrm{~h}$ of illumination) in accordance with earlier results obtained with cucumber [26]. ALA (1 mM) decreased the ascorbate level only by $18 \%$ after $72 \mathrm{~h}$ of incubation. The herbicides did not modify the ascorbate level of pea leaf tissues in dark incubations. Acifluorfen treatments $(10-100 \mu \mathrm{M})$ decreased slightly the DHA levels in the light (data not shown). In contrast, DHA levels were not influenced significantly by ALA treatments.

Acifluorfen $(10-100 \mu \mathrm{M})$ markedly increased the GSH level in illuminated pea leaf discs. In darkness only $100 \mu \mathrm{M}$ acifluorfen elevated the GSH level (Fig. 4). Changes of non-protein thiol levels were similar to those of total glutathione levels after acifluorfen treatments (data not shown). GSH accumulation was already observed in acifluorfen-treated plant tissues $[23,27]$. Our results showed that the elevation of GSH level by acifluorfen in pea leaf discs was only partially light-dependent. It is known that during the degradation of acifluorfen in plants, the first cleavage product forms conjugates with GSH or homoglutathione [28]. It is possible that the plant tissue synthesize more GSH also in the darkness in order to meet greater GSH demand as a result of detoxification reactions. Our results confirm those of Knörzer et al. [13] who also found different responses of ascorbate and GSH in soybean cells exposed to the peroxidizing herbicide oxyfluorfen.

GSH levels were considerably elevated only by high ALA concentrations (1-3 mM). After 48 h of illumination the GSH content rose to $265 \%$ of the control in the presence of $3 \mathrm{mM}$ ALA (Fig. 5). In darkness, ALA (0.1-3 mM) exerted no effect on GSH levels. Changes of non-protein thiol levels were similar to those of total glutathione levels after ALA treatments (data not shown). The effects of ALA on the enzymes of GSH biosynthesis are not known yet. 
In summary, both ascorbate and GSH levels were strongly altered in pea leaf discs by very different singlet oxygen generating reactions. Ascorbate levels markedly decreased in all treatments independently of the site (or mode of action) of singlet oxygen generation. The xanthene dyes are known to act predominantly in the cytoplasm of plant cells [6]. Monuron exerts its oxidative effect in the chloroplasts [6]. Tetrapyrrole derivatives initially accumulate in the plastids (predominantly in the chloroplasts) after acifluorfen and ALA treatments $[4,9,29]$, but the accumulated tetrapyrroles may subsequently leak out of the plastids and photosensitize other cellular compartments [29]. In contrast to ascorbate, the foliar GSH levels were considerably increased by singlet oxygen generators (except by monuron). Singlet oxygen production in both the cytoplasm (by xanthene dyes) and in the plastids (by acifluorfen and ALA) led to marked GSH accumulations. Further studies are necessary to elucidate the effects of singlet oxygen generators on the biosynthetic pathways of both ascorbate and GSH.

\section{Acknowledgements}

The financial support of the Royal Society Hungarian Postdoctoral Fellowship Programme to G. Gullner is gratefully acknowledged.

\section{References}

[1] G. Noctor, C.H. Foyer, Ascorbate and glutathione: keeping active oxygen under control, Annu. Rev. Plant Physiol. Plant Mol. Biol. 49 (1998) 249-279.

[2] J.P. Knox, A.D. Dodge, Singlet oxygen and plants, Phytochemistry 24 (1985) 889-896.

[3] C.H. Foyer, M. Lelandais, K.J. Kunert, Photooxidative stress in plants, Physiol. Plant. 92 (1994) 696-717.

[4] N. Chakraborty, B.C. Tripathy, Involvement of singlet oxygen in 5-aminolevulinic acid-induced photodynamic damage of cucumber (Cucumis sativus L.) chloroplasts, Plant Physiol. 98 (1992) 7-11.

[5] K. Briviba, L.O. Klotz, H. Sies, Toxic and signaling effects of photochemically or chemically generated singlet oxygen in biological systems, Biol. Chem. 378 (1997) 1259-1265.

[6] A.D. Dodge, Herbicide action and effects on detoxification processes, in: C.H. Foyer, P.M. Mullineaux (Eds.), Causes of Photooxidative Stress and Amelioration of Defense Systems in Plants, CRC Press, Boca Raton, 1994, pp. 219-236.
[7] A.J. Enyedi, Induction of salicylic acid biosynthesis and systemic acquired resistance using the active oxygen species generator rose bengal, J. Plant Physiol. 154 (1999) $106-112$.

[8] S.O. Duke, C.A. Rebeiz, Porphyrin biosynthesis as a tool in pest management, in: S.O. Duke, C.A. Rebeiz (Eds.), Porphyric Pesticides: Chemistry, Toxicology, and Pharmaceutical Applications, Symposium Series 559, American Chemical Society, Washington, DC, 1994, pp. 1-16.

[9] M. Matringe, R. Scalla, Studies on the mode of action of acifluorfen-methyl in nonchlorophyllous soybean cells, Plant Physiol. 86 (1988) 619-622.

[10] T. Kömives, G. Gullner, Mechanisms of plant tolerance to photodynamic herbicides, in: S.O. Duke, C.A. Rebeiz (Eds.), Porphyric Pesticides: Chemistry, Toxicology, and Pharmaceutical Applications, Symposium Series 559, American Chemical Society, Washington, DC, 1994, pp. 177-190.

[11] H. Matsumoto, Y. Tanida, K. Ishizuka, Porphyrin intermediate involved in herbicidal action of $\delta$-aminolevulinic acid on duckweed (Lemna paucicostata Hegelm.), Pestic. Biochem. Physiol. 48 (1994) 214-221.

[12] R.S. Bodannes, P.C. Chan, Ascorbic acid as a scavenger of singlet oxygen, FEBS Lett. 105 (1979) 195-196.

[13] O.C. Knörzer, J. Durner, P. Böger, Alterations in the antioxidative system of suspension-cultured soybean cells (Glycine max) induced by oxidative stress, Physiol. Plant. 97 (1996) 388-396.

[14] T. Kömives, G. Gullner, Z. Király, Role of glutathione and glutathione-related enzymes in response of plants to environmental stress, in: P. Csermely (Ed.), Stress of Life. From Molecules to Man, Annals of the New York Academy of Sciences, vol. 851, The New York Academy of Sciences, New York, 1998, pp. 251-258.

[15] L.J. De Kok, M. Graham, Levels of pigments, soluble proteins, amino acids and sulfhydryl compounds in foliar tissue of Arabidopsis thaliana during dark-induced and natural senescence, Plant Physiol. Biochem. 27 (1989) 203-209.

[16] I.K. Smith, Stimulation of glutathione synthesis in photorespiring plants by catalase inhibitors, Plant Physiol. 79 (1985) 1044-1047.

[17] R.R. Wise, A.W. Naylor, Chilling-enhanced photooxidation. Evidence for the role of singlet oxygen and superoxide in the breakdown of pigments and endogenous antioxidants, Plant Physiol. 83 (1987) 278-282.

[18] C.H. Foyer, J. Rowell, D.A. Walker, Measurement of the ascorbate content of spinach leaf protoplasts and chloroplasts during illumination, Planta 157 (1983) 239244.

[19] D.J. Gillham, A.D. Dodge, Chloroplast superoxide and hydrogen peroxide scavenging systems from pea leaves: seasonal variations, Plant Sci. 50 (1987) 105-109.

[20] R. Schupp, H. Rennenberg, Diurnal changes in the glutathione content of spruce needles (Picea abies L.), Plant Sci. 57 (1988) 113-117.

[21] G. Noctor, A.C.M. Arisi, L. Jouanin, K.J. Kunert, H. Rennenberg, C.H. Foyer, Glutathione: biosynthesis, metabolism and relationship to stress tolerance explored in transformed plants, J. Exp. Bot. 49 (1998) 623-647. 
[22] M.J. May, T. Vernoux, R. Sánchez-Fernández, M. Van Montagu, D. Inzé, Evidence for posttranscriptional activation of $\gamma$-glutamylcysteine synthetase during plant stress responses, Proc. Natl. Acad. Sci. USA 95 (1998) 12049-12054.

[23] G. Gullner, T. Kömives, L. Király, Enhanced inducibility of antioxidant systems in a Nicotiana tabacum L. biotype results in acifluorfen resistance, Z. Naturforsch. [C] 46 (1991) 875-881.

[24] O. Arrigoni, L. De Gara, C. Paciolla, A. Evidente, M.C. de Pinto, R. Liso, Lycorine: a powerful inhibitor of L-galactono- $\gamma$-lactone dehydrogenase activity, J. Plant Physiol. 150 (1997) 362-364.

[25] G.L. Wheeler, M.A. Jones, N. Smirnoff, The biosynthetic pathways of vitamin $\mathrm{C}$ in higher plants, Nature 393 (1998) 365-369.
26] W.H. Kenyon, S.O. Duke, Effects of acifluorfen on endogenous antioxidants and protective enzymes in cucumber (Cucumis sativus L.), Plant Physiol. 79 (1985) $862-866$.

[27] A. Schmidt, K.J. Kunert, Lipid peroxidation in higher plants, Plant Physiol. 82 (1986) 700-702.

[28] D.S. Frear, H.R. Swanson, E.R. Mansager, Acifluorfen metabolism in soybean: diphenylether bond cleavage and the formation of homoglutathione, cysteine and glucose conjugates, Pestic. Biochem. Physiol. 20 (1983) 299-310.

[29] H.-P. Mock, U. Keetman, E. Kruse, B. Rank, B. Grimm, Defense responses to tetrapyrrole-induced oxidative stress in transgenic plants with reduced uroporphyrinogen decarboxylase or coproporphyrinogen oxidase activity, Plant Physiol. 116 (1998) 107-116. 